NASA/TM-2000-210045

\title{
Radiation Hardened, Modulator ASIC for High Data Rate Communications
}

Ron McCallister and Robert Putnam

SiCOM, Incorporated, Scottsdale, Arizona

Monty Andro and Gene Fujikawa

Glenn Research Center, Cleveland, Ohio 
Since its founding, NASA has been dedicated to the advancement of aeronautics and space science. The NASA Scientific and Technical Information (STI) Program Office plays a key part in helping NASA maintain this important role.

The NASA STI Program Office is operated by Langley Research Center, the Lead Center for NASA's scientific and technical information. The NASA STI Program Office provides access to the NASA STI Database, the largest collection of aeronautical and space science STI in the world. The Program Office is also NASA's institutional mechanism for disseminating the results of its research and development activities. These results are published by NASA in the NASA STI Report Series, which includes the following report types:

- TECHNICAL PUBLICATION. Reports of completed research or a major significant phase of research that present the results of NASA programs and include extensive data or theoretical analysis. Includes compilations of significant scientific and technical data and information deemed to be of continuing reference value. NASA's counterpart of peerreviewed formal professional papers but has less stringent limitations on manuscript length and extent of graphic presentations.

- TECHNICAL MEMORANDUM. Scientific and technical findings that are preliminary or of specialized interest, e.g., quick release reports, working papers, and bibliographies that contain minimal annotation. Does not contain extensive analysis.

- CONTRACTOR REPORT. Scientific and technical findings by NASA-sponsored contractors and grantees.
- CONFERENCE PUBLICATION. Collected papers from scientific and technical conferences, symposia, seminars, or other meetings sponsored or cosponsored by NASA.

- SPECIAL PUBLICATION. Scientific, technical, or historical information from NASA programs, projects, and missions, often concerned with subjects having substantial public interest.

- TECHNICAL TRANSLATION. Englishlanguage translations of foreign scientific and technical material pertinent to NASA's mission.

Specialized services that complement the STI Program Office's diverse offerings include creating custom thesauri, building customized data bases, organizing and publishing research results ... even providing videos.

For more information about the NASA STI Program Office, see the following:

- Access the NASA STI Program Home Page at http://www.sti.nasa.gov

- E-mail your question via the Internet to help@sti.nasa.gov

- Fax your question to the NASA Access Help Desk at (301) 621-0134

- Telephone the NASA Access Help Desk at (301) 621-0390

- Write to: NASA Access Help Desk NASA Center for AeroSpace Information 7121 Standard Drive Hanover, MD 21076 
NASA/TM-2000-210045

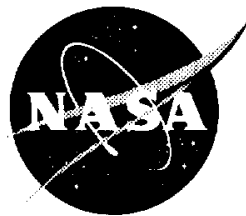

\section{Radiation Hardened, Modulator ASIC for High Data Rate Communications}

Ron McCallister and Robert Putnam

SiCOM, Incorporated, Scottsdale, Arizona

Monty Andro and Gene Fujikawa

Glenn Research Center, Cleveland, Ohio

Prepared for the

18th International Communication Satellite Systems Conference sponsored by the American Institute of Aeronautics and Astronautics Oakland, California, April 10-14, 2000

National Aeronautics and Space Administration

Glenn Research Center 


\section{Acknowledgments}

This work is being funded by NASA Glenn Research Center, under contract number NAS3-99096.

This report contains preliminary findings, subject to revision as analysis proceeds.

Trade names or manufacturers' names are used in this report for identification only. This usage does not constitute an official endorsement, either expressed or implied, by the National Aeronautics and Space Administration.

Available from

NASA Center for Aerospace Information 7121 Standard Drive

Hanover, MD 21076

Price Code: A03
National Technical Information Service 5285 Port Royal Road Springfield, VA 22100

Price Code: A03 


\title{
RADIATION HARDENED, MODULATOR ASIC FOR HIGH DATA RATE COMMUNICATIONS
}

\author{
Ron McCallister and Robert Putnam \\ SiCOM. Inc \\ Scottsdale, Arizona 85260
}

Monty Andro and Gene Fujikawa

National Aeronautics and Space Administration

Glenn Research Center

Cleveland. Ohio 44135

\begin{abstract}
Satellite-based telecommunication services are challenged by the need to generate down-link power levels adequate to support high quality $\left(B E R \cong 10^{12}\right.$ ) links required for modern broadband data services. Bandwidth-efficient Nyquist signaling, using low values of excess bandwidth $(\alpha)$, can exhibit large peakto-average-power ratio (PAPR) values. High PAPR values necessitate high-power amplifier (HPA) backoff greater than the PAPR, resulting in unacceptably low HPA efficiency, Given the high cost of on-board prime power, this inefficiency represents both an economical burden, and a constraint on the rates and quality of data services supportable from satellite platforms. Constantenvelope signals offer improved power-efficiency, but only by imposing a severe bandwidth-efficiency penalty. This paper describes a radiation-hardened modulator which can improve satellite-based broadband data services by combining the bandwidth-efficiency of lo $w$ ' $\alpha$ Nyquist signals with high power-efficiency (negligible HPA backoff).
\end{abstract}

\section{Functional Architecture}

The functional architecture of the modulator module is depicted in figure 1.

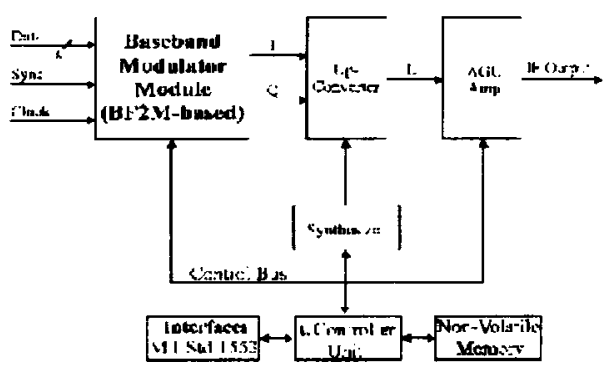

Figure 1. Space-Modulator Module

The Baseband Modulator Module (BMM) translates byte-wide parallel data into baseband quadrature analog signals which are then translated to a desired IF frequency. The key element of the $\mathrm{BMM}$ is a radiationhardened CMOS ASIC which duplicates the functionality of SiCOM's existing BitFLOW2 ${ }^{\mathrm{TM}}$ modulator (BF2M) ASIC; the BF2M functional architecture is depicted in figure 2. Many BF2M functions may be bypassed, and extensive built-in test (BIST) functionality has been incorporated to facilitate both ASIC and module validation testing.

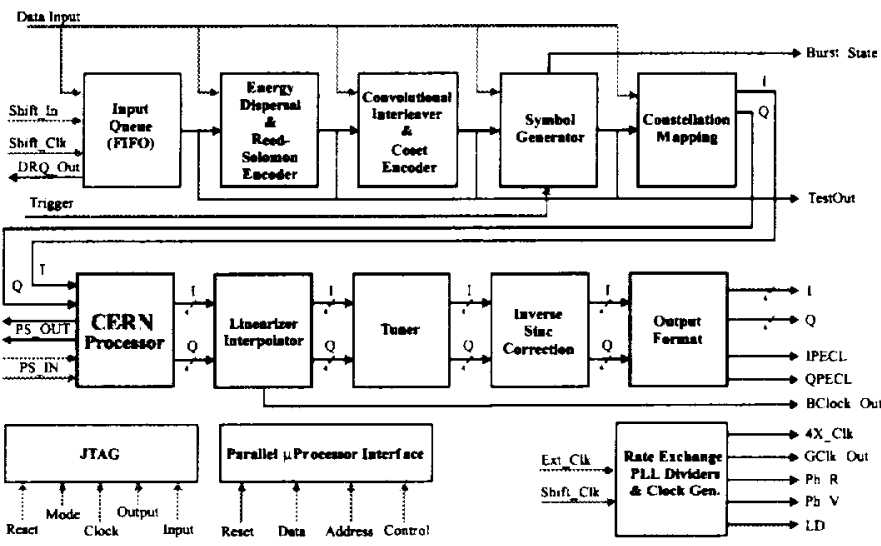

Figure 2. BitFLOW2 Modulator ASIC

\section{Functional Description}

Byte-wide data passes through a re-clocking queue (used to reduce input timing jitter), and is then scrambled. A programmable Reed-Solomon encoder generates a set of parity bytes corresponding to a userdefined block of information bytes. A programmablelength convolutional interleaver distributes received error bursts across multiple RS code blocks. The programmable coset encoder supports numerous convolutional and pragmatic trellis codes derived from the NASA standard Viterbi code by puncturing. The symbol generator groups sets of encoded bits into ntuples, which are then mapped into the user-defined $2^{\text {n }}$ $\{$ I. Q $\}$ constellation points for the selected modulation. 
BF2M supports any arbitrary pattern of constellation points, with any user-defined labeling scheme.

Complex $\{I, Q\}$ values provide the weighting for the programmable pulse shaper; the basic pulse shape is used-defined via the programmable values of sixteen complex coefficients in a tapped-delay-line (TDL) filter. Concatenating successive weighted pulse shapes creates the modulated waveform, which constitutes the input to the constrained-envelope root-Nyquist (CERN) processor. CERN dynamically modifies the complex waveform to achieve very significant PAPR reduction, permitting use of bandwidth-efficient low- $\alpha$ rootNyquist waveforms without requiring large HPA backoff. If activated, CERN accomplishes this key objective with minimal implementation complexity.

An interpolator then processes the complex $\{I, Q\}$ sample stream to maintain a quasi-constant BF2M output sample rate over the entire symbol rate range. The BF2M ASIC also incorporates a programmable complex linearizer, compatible with a wide variety of linearization algorithms, able to rapidly to adapt to any specific HPA AM- AM and AM- PM transfer characteristic. The interpolation/linearization processing supports a non-integer number of samples per symbol to enhance the output signal's spectral purity. The resultant complex sample stream is then processed to provide fine-resolution frequency tuning. Subsuming the fine resolution tuning in digital form greatly simplifies the design of an IF tuner, which may then use large frequency steps and a wide loop bandwidth to greatly reduce its contributed phase noise. The inverse-sinc filter processes the sample stream to pre-compensate for the sine-weighting imposed by digital-to-analog converter (DAC) processing. Finally, the four-fold parallel sample streams are multiplexed together to provide the very high rate complex sample stream for which constitutes the DAC input.

\section{Capabilities}

The BF2M scrambler conforms to the DVB-S standard. defined by the polynomial $p(x)=x^{15}+x^{14}+1$. The ReedSolomon encoder subsumes the DVB-S standard, with a field generator polynomial $p(x)=x^{8}+x^{4}+x^{3}+x^{2}+1$, and primitive field element $\lambda=02_{\text {hex }}$, but supporting any shortened code-block size with 16 parity bytes, not only the DVB-S standard block length of 204 . A userdefinable synchronization byte must be included between all RS code blocks. The convolutional interleaver conforms to the DVB-S standard. a Ramsey type III approach with interleaving depth 12 and depth (M) of 17 .

\section{Error correction coding}

The coset encoder supports all modes and code rates of the DVB-S standard inner convolutional encoder, as well as all DVB-SNG standard trellis codes (8PSK, rates $2 / 3,5 / 6$ and $8 / 9$, and $16 \mathrm{QAM}$, rates $3 / 4$ and $\cdot$ ); all unique interleaving associated with DVB-SNG 8PSK and 16QAM is also incorporated. In addition to fully complying with the DVB-S and DVB-SNG standards, the coset encoder also supports higher-order modulations, including 32QAM, 64QAM, 128QAM and 256QAM; each of these modulations is supported with a pair of programmable inner code rates. For example, 64QAM can use an inner code rate of either $5 / 6$ or 11/12; 128QAM can use an inner code rate of either $6 / 7$ or $13 / 14$.

\section{Power-efficient modulation}

In addition to supporting high-order standard QAM modulations, the BF2M ASIC supports a novel new class of constellations referred to as SiQAM (SiliconQAM). High-power amplifiers (HPAs) are peak-powerlimited, rather than average-power-limited; SiQAM exploits this fact by quasi-uniformly distributing the modulation's constellation points within the constraints of a unit circle, rather than the inscribed square (QAM). As figure 3 shows, uniformly spreading constellation points within the larger peak-power constraint (unit circle) should theoretically offer to improve BER performance by nearly $2 \mathrm{~dB}$ in this manner. $A$ far more sophisticated analysis validates this conclusion.'

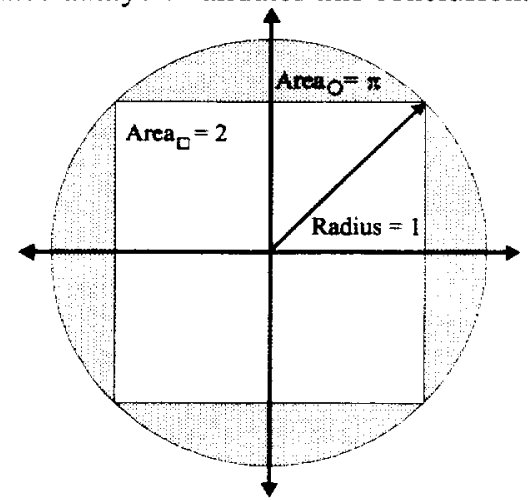

Figure 3. SiQAM's CompetitiveEdge

Simulations confirm that SiQAM can improve bit-errorrate (BER) by nearly $1.5 \mathrm{~dB}$ over conventional QAM modulation.

\section{Peak-to-average-power-ratio (PAPR) reduction} The BF2M ASIC provides a fully-programmable pulse shape, supporting a wide range of root-Nyquist excess bandwidth values $(0.125<\alpha<0.5)$, including predistortion for linear channel distortion. For known distortion, it is better to pre-distort rather than attempt to equalize the combined signal plus noise at the receiver. While pre-distortion addresses linear channel distortion, a different approach is required to address the impacts of the nonlinear distortion associated with the satellite's HPA. The classic HPA challenge involves the tradeoff between improving power-efficiency by minimizing backoff, while assuring that the spectral regrowth induced by low backoff still satisfies the transmitter's spectral mask constraints. 
A well-known problem with the very bandwidthefficient low- $\alpha$ pulses is the fact that they exhibit large and undesirable PAPR values, ${ }^{2}$ requiring many $\mathrm{dB}$ of additional backoff to avoid spectral splatter at the HPA output. Figure 4 depicts the sensitivity of PAPR to excess bandwidth $(\alpha)$ for several of the most common modulation types. 8PSK exhibits strong PAPR sensitivity for $\alpha<0.4$, increasing by $3.5 \mathrm{~dB}$ for an $\alpha$ value of 0.12 . While bandwidth-efficiency improves by fully $25 \%$ as $\alpha$ is reduced from 0.4 to 0.12 , the PAPR increases by nearly $3.5 \mathrm{~dB}$, exacting a severe cost in power-efficiency. For satellite-based links, this tradeoff is seldom attractive.

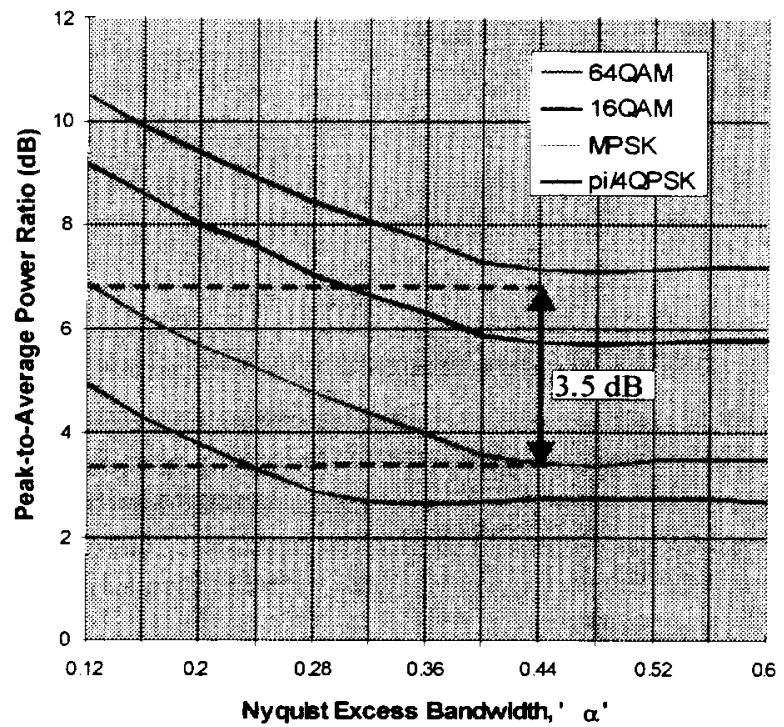

Figure 4. Sensitivity of PAPR to Excess Bandwidth

The BF2M ASIC incorporates a recent breakthrough called CERN (constrained-envelope root-Nyquist) signaling which directly addresses this PAPR sensitivity problem. CERN's conceptual basis is readily appreciated in terms of the statistics of the signal magnitude, expressed as a probability-density-function (pdf). The magnitude pdf of low- $\alpha$ root-Nyquist waveforms exhibits a very long tail, as depicted in figure 5. The mechanisms for spectral regrowth may readily be appreciated if the nonlinear HPA characteristic is replaced by its ideal linearized equivalent, also depicted in figure 5 . Sensitivity of spectral regrowth to nonlinear amplification is such that if any portion of the magnitude pdf extends beyond the linearized HPA breakpoint, unacceptable spectral regrowth occurs.

Consequently one must operate an HPA with many dB of backoff, where the degree of backoff is determined by signal peak magnitude. It is instructive to consider the impact of using bandwidth-efficient root-Nyquist

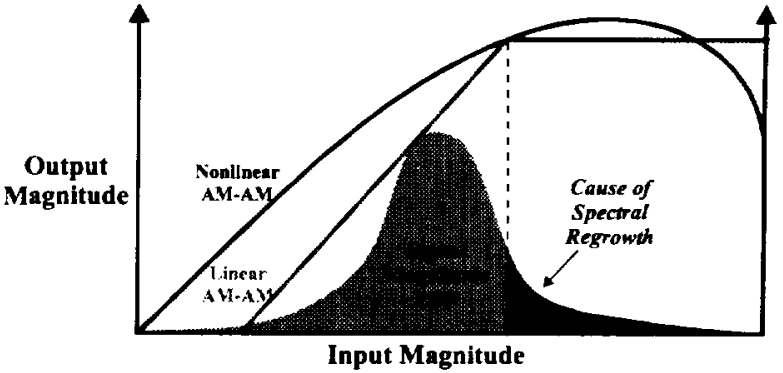

Figure 5. HPA-induced Spectral Regrowth Mechanism

signaling on the peak signal magnitude. Although 8PSK is often thought of as a constant-envelope signal, use of a bandwidth-efficient low- $\alpha$ root-Nyquist waveform introduces large peak signal excursions. The lighter curve in figure 6 depicts the simulated signal trajectory of an 8PSK signal with an $\alpha=0.13$ root-Nyquist waveform. The peak magnitude of this signal is nearly twice the magnitude of the unit circle upon which the 8 PSK constellation points are located.

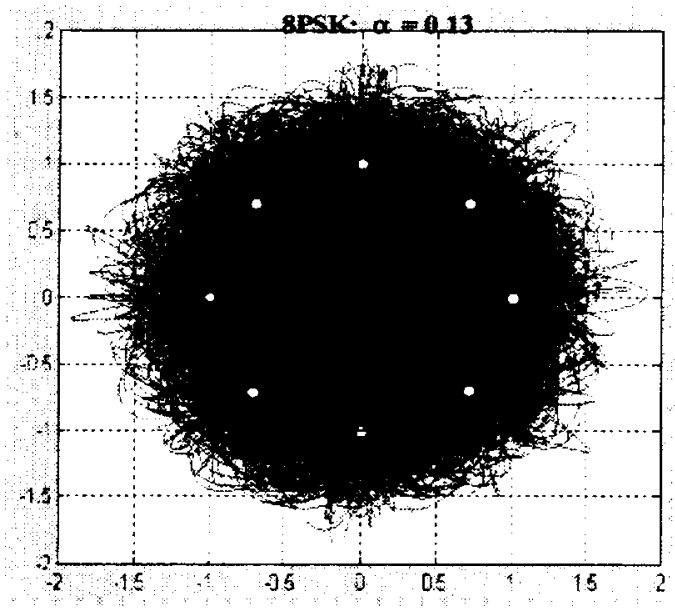

Figure 6. Vector Plot of 8PSK Signal

The darker signal trajectory corresponds to the same signal when CERN processing is employed. Even though the signal spectrum remains identical. the peak has been reduced by over $3 \mathrm{~dB}$. Consequently, the HPA may be operated with $3 \mathrm{~dB}$ less backoff for the same degree of spectral regrowth. The net effect is that the signal at the HPA output has nearly $3 \mathrm{~dB}$ greater average power using CERN than using conventional root-Nyquist signaling. Recall that, while the link biterror-rate (BER) is driven by the average signal power. spectral regrowth at the transmitter is driven by peak signal power. PAPR reduction processing addresses the need to maximize the received average signal power subject to the peak power constraint on the HPA. 
CERN's revolutionary alteration of the tradeoff between bandwidth-efficiency and power-efficiency merits further clarification. Figure 7 depicts the simulated output spectrum of an 8PSK low- $\alpha$ rootNyquist signal subjected to ideal clipping at various levels. Severe spectral regrowth occurs even at a clipping level over 1.6 times the radius of the 8PSK constellation. In contrast, figure 8 depicts the corresponding spectral plot in which CERN's PAPRreduction processing has been employed: even severe clipping introduces only modest spectral regrowth.

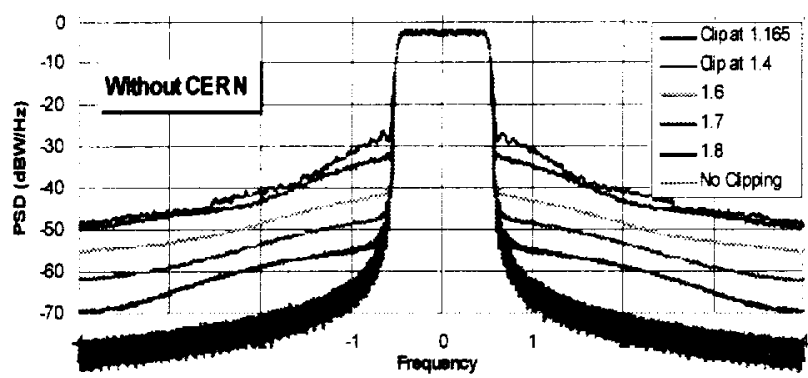

Figure 7. Spectral Regrowth: Clipped Signal

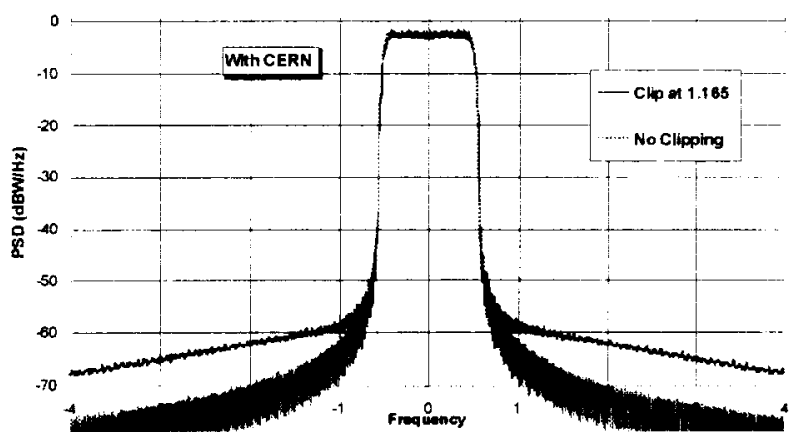

Figure 8. Spectral Regrowth: Clipped CERN Signal

Conventional root-Nyquist signals exhibit a magnitude probability-density-function (pdf) with a very slowly decaying tail. Figure 9 depicts both this phenomenon and the abrupt truncation of the tail of the signal's magnitude pdf which constitutes the physical basis for CERN's PAPR reduction.

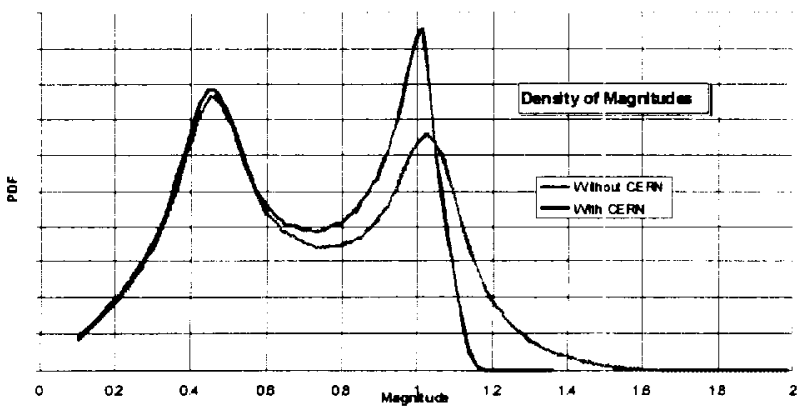

Figure 9. Magnitude pdfs: with and w/o CERN
Figure 10 converts magnitude pdfs into corresponding cumulative density functions (cdfs) to facilitate quantification of CERN's benefit. From figures 7, 8, and 10 , we can see that acceptable levels of spectral regrowth require less than $0.01 \%$ clipping, which occurs at clipping levels of 1.165 and 1.7 for CERN'd and conventional signals, respectively. Thus, CERN processing reduces HPA backoff by about $3.3 \mathrm{~dB}$ $\left[=20 \log _{10}(1.7 / 1.165)\right]$.

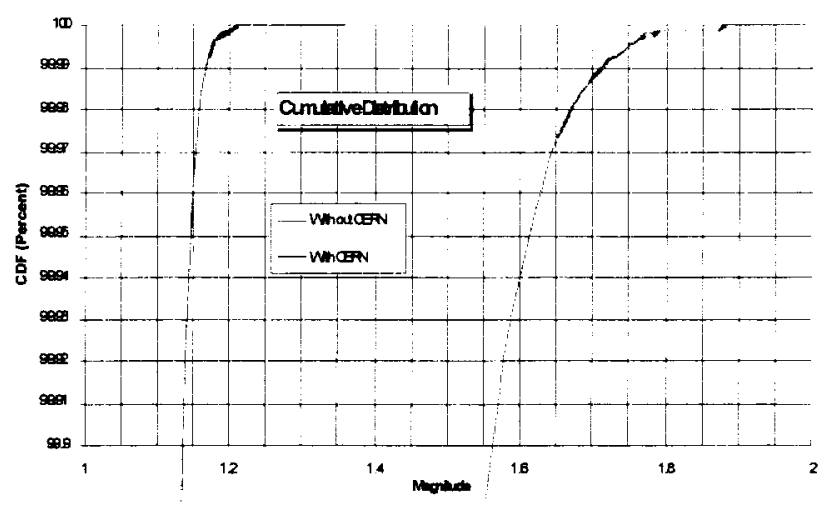

Figure 10. Magnitude Cumulative Density Functions

CERN's net benefit is less than the amount of HPA backoff reduction, since CERN processing introduces a signal-dependent noise, resulting in an attendant BER degradation. Figure 11 depicts the impact of this noise on link BER; in this case, CERN-noise causes a $1.2 \mathrm{~dB}$ BER degradation.

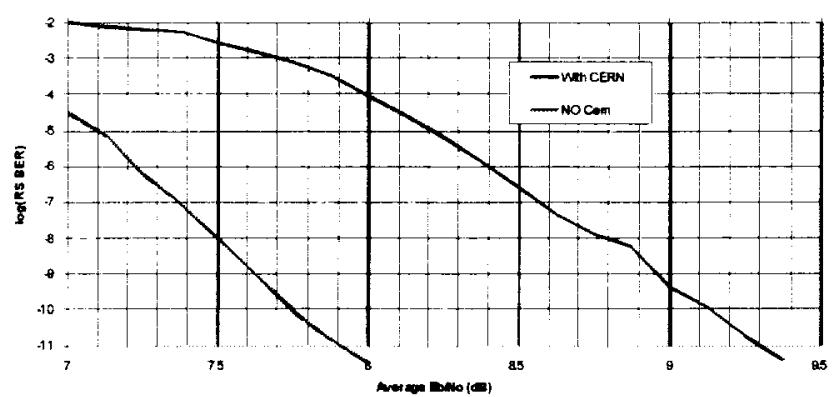

Figure 11. CERN-noise BER Degradation

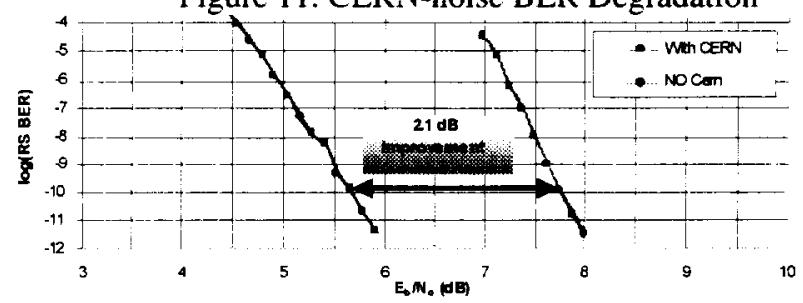

Figure 12. Net BER Improvement with CERN

\section{Link Performance}

The innovative modem architecture. including the modulator described herein incorporates, in addition to SiQAM and CERN, an unprecedented degree of 
flexibility for supporting the demand of any wireless link for modulation and coding which is optimal for that link"s unique pathologies and signal-to-noise ratio. Figure 13 depicts modem BER-vs- $E_{b} N_{o}$ performance for a variety of modulation and coding configurations.

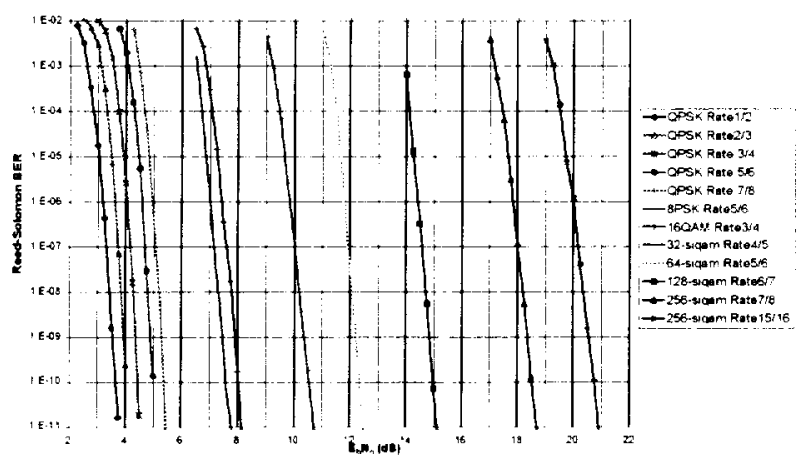

Figure 13. Modem Performance

With sufficient signal-to-noise ratio, the modem architecture \& ASICs will support data rates up to 1 Gbps (256 QAM. uncoded).

\section{ASIC Physical/Radiation Characteristics}

The ASIC will be packaged in a 352-pin quad flat-pack. $3^{* *}$ on a side. with 6-8 watts at maximum clock rate. The ASIC will be produced in a process capable of $100 \mathrm{~K}$ rads ( $\mathrm{Si}$ ) total radiation dose, with $\mathrm{LET}_{\mathrm{TH}} \geq 30 \mathrm{MEV}$. and no latchup.

\section{Potential Applications}

High data rate communications technologies are required for NASA's science missions and similar commercial space ventures to meet the demands of future space and Earth-observing science instruments and communications/data processing systems. The radiation hardened modulator module has potential application in meeting the demands for more efficient use of spectrum as NASA and commercial systems transition from S-and X-band to Ka-band frequencies. For example. with higher-order, bandwidth- and powerefficient modulation and coding, this unit can be coupled with a high efficiency. $26 \mathrm{GHz}$ active phased array antenna ${ }^{3}$ to enable use of the wider frequency allocations available for RF downlinks. NASA Glenn Research Center (GRC). along with NASA Goddard Space Flight Center (GSFC), are proposing to demonstrate this technology on future Earth science flight opportunities, such as the National Polar-orbiting Operational Environmental Satellite System (NPOESS) follow-on technology demonstration.

A high-speed modulator based on this design. can be applied to GRC's Direct Data Distribution $\left(D^{3}\right)^{4}$
Project. which seeks to demonstrate key technologies for high rate downlinks $(622 \mathrm{Mb} / \mathrm{s})$ from low earth orbit direct to Earth. The project will fly an experimental communication package onboard the Shuttle with integrated $\mathrm{Ka}$ band $(19 \mathrm{GHz})$ phased array antenna and high-speed modulator demonstrating high data rate communications to small. low cost ground terminals.

In addition. programs such as the International Space Station continue to seek out newer technologies for high data rate links direct to Earth or via the next generation of TDRSS spacecraft. Future space science missions will seek extremely bandwidth-efficient. high data rate links (for instance, ARISE ${ }^{5}$ requires $8 \mathrm{Gbit} / \mathrm{sec}$ in a $1 \mathrm{GHz}$ bandwidth) in small, lightweight packages. Space environmental effects programs may also benefit from these technologies. where the use and characterization of rad-hard ICs are critical to the success of the missions.

\section{Summary}

The development of the ASIC modulator chip is scheduled for completion in January 2001, with plans of integrating the ASIC chip with additional electronics to develop a space ready modulator module. The modulator module will utilize the rad-hard ASIC with associated $\mathrm{D} / \mathrm{A}$ converters. interface and control circuitry and $\mathrm{RF}$ electronics aimed at meeting the future high data rate communications needs of NASA missions. Plans are to develop the companion demodulator ASIC as funding becomes available.

This technology will demonstrate the viability of bandwidth efficient modulation, when combined with non-linear amplification mitigation techniques. that will meet the needs of future NASA missions which have typically relied on bandwidth inefficient schemes in the past. The programmability and adaptability of the current design will meet the future changing needs of next generation NASA missions and commercial applications allowing for the seamless integration of data between Government and commercial systems.

\section{Acknowledgment}

This work is being funded by NASA Glenn Research Center, under contract number NAS3-99096.

\footnotetext{
${ }^{1}$ R. Müller, et al., "Multilevel Coding for Peak Power Limited Complex Gaussian Channels," Proceedings of the 1997 Int'l Symposium of Information Theory. Ulm, Germany.

${ }^{2}$ Miller and R. O'Dea, "Peak Power and Bandwidth Efficient Linear Modulation," IEEE Trans. Commun.. vol. 46. pp. 1639-1648, Dec. 1998.
} 
${ }^{3}$ Pellerano, F., "High Rate User Ka-Band Phased Array Antenna," Ka-Band Commercialization Workshop, GSFC, March 1998.

${ }^{4}$ Wald, L. et al., "An Advanced Ka Band Phased Array Communication System at Commercial Frequencies," Space Technology and Applications International Forum, Albuquerque, New Mexico, January 30February 3, 2000.

${ }^{5}$ J.S. Ulvestad, R.P. Linfield, and J.G. Smit, "ARISE: The Next Generation Space VLBI Mission," AIAA 1995 Space Programs and Technologies Conference, September 26-28, 1995, Huntsville, AL. 
Public reporting burden for this collection of intormation is estimated to average 1 hour per response, including the time for reviewing instructions, searching existing data sources, gathering and maintaining the data needed, and completing and reviewing the collection of information. Send comments regarding this burden estimate or any other aspect of this collection of information, including suggestions for reducing this burden. to Washington Headquarters Services, Directorate for Information Operations and Reports. 1215 Jefferson Davis Highway, Suite 1204, Arlington. VA 22202-4302, and to the Otfice of Management and Budget, Paperwork Peduction Project (0704-0188), Washington, DC 20503.

\begin{tabular}{|l|c|c|}
\hline 1. AGENCY USE ONLY (Leave blank) & $\begin{array}{c}\text { 2. REPORT DATE } \\
\text { June } 2000\end{array}$ & $\begin{array}{c}\text { 3. REPORT TYPE AND DATES COVERED } \\
\text { Technical Memorandum }\end{array}$
\end{tabular}

\section{TITLE AND SUBTITLE}

5. FUNDING NUMBERS

Radiation Hardened, Modulator ASIC for High Data Rate Communications

6. AUTHOR(S)

Ron McCallister, Robert Putnam, Monty Andro, and Gene Fujikawa

WU-632-6E-51-00

NAS3-99096 SBIR

7. PERFORMING ORGANIZATION NAME(S) AND ADDRESS(ES)

National Aeronautics and Space Administration

John H. Glenn Research Center at Lewis Field

Cleveland, Ohio 44135-3191

B. PERFoRMING ORGANIZATION REPORT NUMBER

E-12246

9. SPONSORING/MONITORING AGENCY NAME(S) AND ADDRESS(ES)

10. SPONSORINGMONITORING

National Aeronautics and Space Administration

Washington, DC 20546-0001 AGENCY REPORT NUMBER

NASA TM-2000-210045

\section{SUPPLEMENTARY NOTES}

Prepared for the 18th International Communication Satellite Systems Conference sponsored by the American Institute of Aeronautics and Astronautics, Oakland, California, April 10-14, 2000. Ron McCallister and Robert Putnam, SiCOM, Incorporated, 7585 East Redfield Road, Scottsdale, Arizona 85260 (work funded by NASA Contract NAS3-99096). Monty Andro and Gene Fujikawa. NASA Glenn Research Center. Responsible person, Monty Andro, organization code 5650, (216) 433-3492.

\section{2a. DISTRIBUTION/AVAILABILITY STATEMENT}

\section{2b. DISTRIBUTION CODE}

Unclassified - Unlimited

Released as Publicly Available April, 2000

Subject Category: 17

Distribution: Nonstandard

This publication is available from the NASA Center for AeroSpace Information. (301) 621-0390.

13. ABSTRACT (Maximum 200 words)

Satellite-based telecommunication services are challenged by the need to generate down-link power levels adequate to support high quality $\left(B E R \cong 10^{12}\right)$ links required for modern broadband data services. Bandwidth-efficient Nyquist signaling, using low values of excess bandwidth $(\alpha)$, can exhibit large peak-to-average-power ratio (PAPR) values. High PAPR values necessitate high-power amplifier (HPA) backoff greater than the PAPR, resulting in unacceptably low HPA efficiency. Given the high cost of on-board prime power, this inefficiency represents both an economical burden, and a constraint on the rates and quality of data services supportable from satellite platforms. Constant-envelope signals offer improved power-efficiency, but only by imposing a severe bandwidth-efficiency penalty. This paper describes a radiationhardened modulator which can improve satellite-based broadband data services by combining the bandwidth-efficiency of lo $w-\alpha$ Nyquist signals with high power-efficiency (negligible HPA backoff).

\section{SUBJECT TERMS}

Digital modulation; Radiation hardened

15. NUMBER OF PAGES 12

16. PRICE CODE

$$
\mathrm{AO} 3
$$

\begin{tabular}{|c|c|}
\hline $\begin{array}{c}\text { 17. SECURITY CLASSIFICATION } \\
\text { OF REPORT } \\
\text { Unclassified }\end{array}$ & $\begin{array}{c}\text { 18. SECURITY CLASSIFICATION } \\
\text { OF THIS PAGE } \\
\text { Unclassified }\end{array}$ \\
\hline
\end{tabular}

19. SECURITY CLASSIFICATION
OF ABSTRACT
Unclassified

20. LIMITATION OF ABSTRACT

NSN 7540-01-280-5500 